\title{
Repeated dose oral toxicity of inorganic mercury in wistar rats: biochemical and morphological alterations
}

\author{
T. J. Sheikh, B. J. Patel, D. V. Joshi, R. B. Patel and M. D. Jegoda \\ Department of Veterinary Pathology, \\ College of Veterinary Science and Animal Husbandry, \\ S. D. Agricultural University, Sardar Krushinagar - 385 506, Gujarat, India \\ Corresponding author: T. J. Sheikh, email: drsheikh2@yahoo.co.in \\ Received: 05-01-2013, Revised: 09-04-2013, Accepted: 09-04-2013, Published online: 13-06-2013
}

\section{How to cite this article:}

Sheikh TJ, Patel BJ , J oshi DV, Patel RB and J egoda MD (2013) Repeated dose oral toxicity of inorganic mercury in wistar rats: biochemical and morphological alterations, Vet World 6(8): 563-567, doi: 10.5455/vetworld.2013.563-567

\begin{abstract}
Aim: The study was conducted to find out the possible toxic effect of mercuric chloride $\left(\mathrm{HgCl}_{2}\right)$ at the histological, biochemical, and haematological levels in the wistar rats for 28 days.

Materials and Methods: The biochemical and hematological alteration were estimated in four groups of rat (each group contain ten animals), which were treated with 0 (control), 2, 4, and $8 \mathrm{mg} / \mathrm{kg}$ body weight of $\mathrm{HgCl}_{2}$ through oral gavage. At the end of study all rats were sacrificed and subjected for histopathology.

Result: A significantly $(P<0.05)$ higher level of serum alanine amino transferase (ALT), gamma Glutamyle Transferase, and creatinine were recorded in treatment groups, while the level of alkaline phosphtase (ALP) was significantly decreased as compared to the control group. The toxic effect on hematoclogical parameter was characterized by significant decrease in hemoglobin, packed cell volume, total erythrocytes count, and total leukocyte count. Gross morphological changes include congestion, severe haemorrhage, necrosis, degenerative changes in kidneys, depletion of lymphocyte in spleen, decrease in concentration of mature spermatocyte, and edema in testis. It was notable that kidney was the most affected organ.
\end{abstract}

Conclusion: Mercuric chloride $\left(\mathrm{HgCl}_{2}\right)$ caused dose-dependent toxic effects on blood parameters and kidney.

Keywords: biochemical, haematological, mercuric chloride, morphological, toxicity, wistar rat

\section{Introduction}

Health condition of an animal/human is characterized by its metabolic activities of vital organs such as kidney, liver and, brain, out of which liver and kidney are most important. The animals can be exposed to mercury contamination from water, soil, air, and sometimes from food sources like fish protein concentrates or the accidental use of treated seed grain [1]. Having been absorbed from the digestive tract, mercury forms a long lasting suspension with the thionin, forming metallothioneins which deserve an important role in afterwards metabolism of this inorganic compound. So it has been a great concern for the eco- toxicologist that if chronic ingestion of inorganic mercury can produce different type of cumulative toxicity or carcinogenicity in different vital organs in animals. However, more intensive and systematical investigations are needed to evaluate commutative organ toxicity to whole body. Kidneys mainly renal -cortex and liver are considered to be the most susceptible organs in the case of exposure to mercury [2]. As transport of organic substances is the hallmark of functional kidney [3]. The toxicity of $\mathrm{Hg}$ (considered as nephortoxicants) is largely due to the high affinity to sulfahydral $(\mathrm{SH})$ groups $[4,5]$. The sulfahydral $(\mathrm{SH})$ groups are seen in some diffusible

This article is an open access article licensed under the terms of the Creative Commons Attribution License (http://creativecommons. org/licenses/by/2.0) which permits unrestricted use, distribution and reproduction in any medium, provided the work is properly cited. low molecular weight substance such as cysteine (Cys), CoA (Coenzyme-A) but importantly are located in most proteins. For nephrotoxicants (particularly mercury) toxicity mitochondria plays specific role and it can also provide the opportunity as the subcellular target of nephrotoxicants $[6,7,8]$. Exposure to any foreign substance can disturb the metabolic pathways of that particular organ. Mercury toxicity is a significant clinical entity [9] and as it is ubiquitous in the environment, it poses serious risks to large animal's health, which consume drinking water contaminated with large amount metals mostly mercury.

Hence, the present study was designed to observed the toxic effect on blood biochemistry, hematology and histopathology in wistar rat after 28 days repeated oral dose of inorganic mercury (mercuric chloride) administration.

\section{Materials and Methods}

Male wistar rats of 5-7 weeks old were procured from the Zydus Research centre, Zydus pharmaceutical company (Ahmedabad - India). The animals were kept under controlled conditions of temperature $\left(22 \pm 3^{\circ} \mathrm{C}\right)$ and humidity $(60 \pm 5 \%)$. They were given pellet food (Amrut feeds Ltd., Pune, India) and drinking water ad libitum. A twelve hour day and night cycle was maintained in the animal house.

Ethical approval: The experimental protocol met the national guidelines (CPCSEA) on the proper care and use of animals in the laboratory research. The 
Table-1. Comparative haematological values in mercuric chloride treated rats at different intervals.

\begin{tabular}{|c|c|c|c|c|}
\hline \multirow[t]{2}{*}{ Parameters } & \multirow[t]{2}{*}{ Groups } & \multicolumn{3}{|c|}{ Days interval } \\
\hline & & 0 & 14 & 28 \\
\hline \multirow[t]{4}{*}{ Hemoglobin(g/dl) } & I & $17.49 \pm 0.20^{\mathrm{a}}$ & $16.35 \pm 0.41^{a}$ & $15.97 \pm 0.43^{\mathrm{a}}$ \\
\hline & II & $17.49 \pm 0.22^{\mathrm{a}}$ & $15.87 \pm 0.57^{\mathrm{ab}}$ & $13.14 \pm 0.53^{b}$ \\
\hline & III & $17.51 \pm 0.23^{\mathrm{a}}$ & $15.34 \pm 0.62^{b}$ & $12.91 \pm 0.50^{\mathrm{bc}}$ \\
\hline & IV & $17.51 \pm 0.25^{\mathrm{a}}$ & $14.75 \pm 0.79^{\circ}$ & $12.05 \pm 0.46^{\mathrm{c}}$ \\
\hline \multirow[t]{4}{*}{ Packed cell volume (\%) } & I & $52.49 \pm 0.61^{\mathrm{a}}$ & $49.08 \pm 1.25^{\mathrm{a}}$ & $47.93 \pm 1.30^{\mathrm{a}}$ \\
\hline & II & $52.50 \pm 0.68^{\mathrm{a}}$ & $47.62 \pm 1.77^{\mathrm{ab}}$ & $39.45 \pm 1.61^{\mathrm{b}}$ \\
\hline & III & $52.53 \pm 0.61^{\mathrm{a}}$ & $46.04 \pm 1.92^{\mathrm{b}}$ & $38.75 \pm 1.52^{\mathrm{bc}}$ \\
\hline & IV & $52.38 \pm 0.70^{\mathrm{a}}$ & $44.31 \pm 2.38^{\mathrm{c}}$ & $36.16 \pm 1.39^{\circ}$ \\
\hline Total erythrocyte count & I & $7.86 \pm 0.04^{\mathrm{a}}$ & $7.94 \pm 0.03^{\mathrm{a}}$ & $7.86 \pm 0.06^{\mathrm{a}}$ \\
\hline \multirow[t]{3}{*}{ (million/c umm) } & II & $7.85 \pm 0.05^{\mathrm{a}}$ & $7.97 \pm 0.05^{\mathrm{a}}$ & $7.64 \pm 0.06^{\mathrm{ab}}$ \\
\hline & III & $7.84 \pm 0.04^{\mathrm{a}}$ & $7.94 \pm 0.04^{\mathrm{a}}$ & $7.15 \pm 0.11^{\mathrm{c}}$ \\
\hline & IV & $7.84 \pm 0.03^{\mathrm{a}}$ & $7.91 \pm 0.04^{\mathrm{a}}$ & $6.15 \pm 0.12^{d}$ \\
\hline & I & $14.34 \pm 0.03^{\mathrm{a}}$ & $14.68 \pm 0.16^{\mathrm{a}}$ & $15.69 \pm 0.14^{\mathrm{a}}$ \\
\hline \multirow{3}{*}{ (thousand/cumm) } & II & $14.33 \pm 0.01^{a}$ & $14.66 \pm 0.16^{a}$ & $14.42 \pm 0.14^{a}$ \\
\hline & III & $14.34 \pm 0.01^{a}$ & $14.58 \pm 0.16^{b}$ & $13.90 \pm 0.17^{b}$ \\
\hline & IV & $14.35 \pm 0.01^{\mathrm{a}}$ & $14.40 \pm 0.17^{\circ}$ & $11.61 \pm 0.22^{\mathrm{c}}$ \\
\hline
\end{tabular}

Means bearing different superscript within same row differ significantly $(\mathrm{a}, \mathrm{b}, \mathrm{c}, \mathrm{ab}, \mathrm{bc} P<0.05)$.

experimental protocol was approved by the Institutional Animal Ethics Committee (IAEC) and OECD-407 was followed.

Procurement of Metal: Mercuric chloride was obtained from Merck India Ltd. (Mumbai India), and dissolved in the distilled water and administered per OS route.

Experimental design: Experiment was conducted for four weeks. The animals were divided into four groups, each group contain 10 animals $(n=10)$. In preliminary study it was found that LD50 of $\mathrm{HgCl}_{2}$ was $40 \mathrm{mg} / \mathrm{kg}$ body wt. Daily oral dosing was carried out as:

Group I - Controlled animals- vehicle (normal saline), Group II - $2.0 \mathrm{mg} / \mathrm{Kg} \mathrm{HgCl}_{2}$,

Group III - $4.0 \mathrm{mg} / \mathrm{Kg} \mathrm{HgCl}_{2}$,

Group IV - $8.0 \mathrm{mg} / \mathrm{Kg} \mathrm{HgCl}_{2}$

Blood samples were collected on 0,14 and 28 day of experiment. Blood was collected similar time of day and by retro-orbital venous plexus puncture under ethyl-ether anesthesia.

Parameters tested: All the biochemical parameters viz. Alanine amino trasferase (ALT), gamaglutamyle traspeptidase (GGT), alkaline phosphatase (ALP) and creatinine, were analyzed by using respective Accucare Diagnostic Kit (LAB-CARE Diagnostic India Pvt. Ltd., Mumbai). While Hematological parameters viz. haemoglobin, hematocrit, total leukocyte count, total erythrocyte count, and differential leukocyte count were estimated by blood auto-analyzer (Beckman coulter). After 28 days all remaining rats were scarified and tissues like kidneys, liver, spleen, lung, intestine, heart and brain had obtained from necropsied animals, and fixed in neutral buffer formalin and processed for hematoxylin and eosin staining.

Statistical analysis: Data are expressed as Mean and standard error (SE). Analysis of variance (ANOVA) was used to find out significance $(P<0.05$ was considered) variation in the different studied groups [10].

\section{Results}

The effects of mercuric chloride on selected liver and renal function biochemical tests (ALT, GGT, ALP and creatinine concentration in serum) in animals are presented in bar diagram (Plate-1). After Administration of mercuric chloride to rats, resulted in a statistically significant increase of ALT, gamma glutamyl transferase and creatinine concentration in serum in relation to their respective control groups. The above mentioned enzymes were increased as the dose increased. However, the activity of serum alkaline phosphatase was significantly decrease after $14^{\text {th }}$ and $28^{\text {th }}$ days of treatment when compared to its controls.

In Haematology, after 28 days post-treatment with $\mathrm{HgCl}_{2}$ there were significantly $(P<0.05)$ decrease in haemoglobin $(\mathrm{Hb})$, packed Cell Volume (PCV), total erythrocyte count (TEC) and Total leucocyte count (TLC) as shown in Table-1. In differential Leukocyte Count there was significantly decrease in lymphocyte count while neutrophils, monocyte and eosiniphils increased significantly as compare to control.

There were not any gross lesions in any of the organs during postmortem. Histologiclly mutifocally with the kidney parenchyma there were areas of haemorrhage, necrosis, infiltration of mononuclear cells, hypercellularity, degenerative prominent nuclei, narrowing of lumen, low amount of proteineous cast in lumen of convoluted tubules (Figure-1). Brain slide showed demyelination (Figure-2) of nerve fibres. There was a depletion of lymphocytes in spleen. In testis, the concentration of mature spermatocyte decrease significantly (Figure-3) and degeneration in germinal cell layer with edematous fluid found inbetween semineferous tubule. Severe degree of fatty changes, vacuolization (Figure-4), karyorrhexis in hepatocytes, sinusoidal dilatation and mononuclear cell infiltration were observed in liver. Sloughing of villi was observed in intestine. The lesions in mercury treated rats was in dose depended manner. 


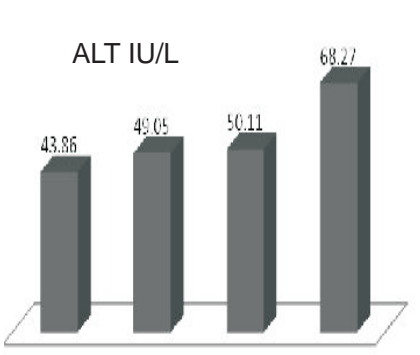

Gr.1 Gr.2 Gr.3 Gr.4

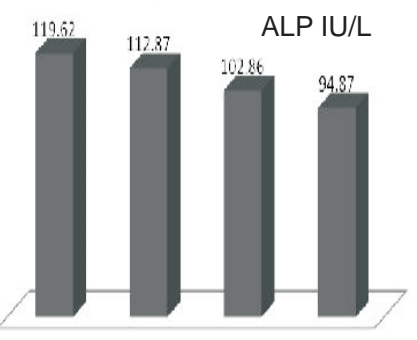

Gr.1 Gr.2 Gr.3 Gr.4

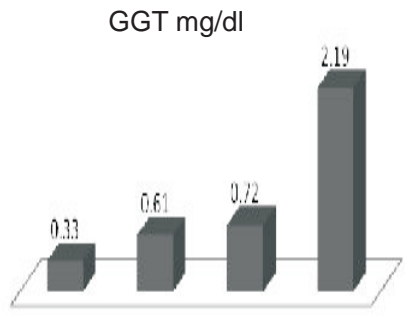

Grp.1 Gip.2 Grp.3 Grp.4

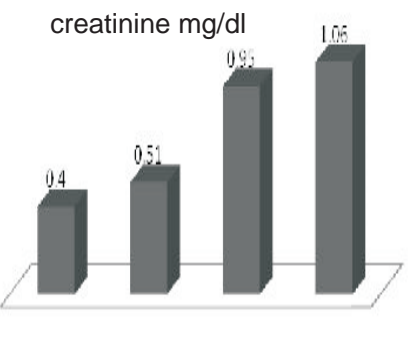

Grp.1 Grp.2 Grp.3 Grp.4

Plate-1. Biochemical estimation for ALT, ALP, GGT and creatinine on 28th day of experiment

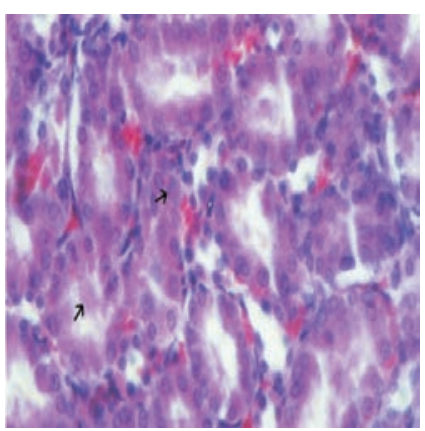

Figure-1. Kidney showing hae- Figure-2. Brain; demyelination in morrhages and accumulation of cerebellum proteineous cast (arrow) into convoluted tubule.

\section{Discussion}

In the present investigation marked increase in liver- ALT under stress of mercury has been observed. This elevation in above said parameters has been well supported by Toshiko et al.,[11], Ejebe et al., [12], Madhu et al.,[13] and El-Dermadash [14]. A significant $(P<0.05)$ increase in serum Gamma glutamyl transferase activity was observed in all treatment groups on 28th day post-treatment as compare to control of that group. Hepatic gland issite for biotransformation by which the toxic compound (metal) has been transformed in less harmful form to reduce toxicity. However, this will damage the liver cells and produce hepatotoxicity. ALT is an enzyme that helps metabolize protein. When the liver (hepatocyte) is damaged, alanine amino transferase enzymes released from hepatocyte in the bloodstream. ALT is a cytoplasmic enzyme, which is more specific for the hepatocyte of liver than aspartate amino transaminase for small animals. The decrease in serum ALP was observed on 28th day in all treatment groups as compare to control of that groups. The decreased in ALP was also observed by Merzoug et al., [15]. This might because of changes in the liver, it is closely connected with lipid membrane in the canalicular zone, so that any disturbance with the bile excretion, whether extra-hepatic or intra-hepatic leads to decrease in serum alkaline phosphatase level [15].

The mean values of serum creatinine was significantly increase as compare to control on 28th day. This elevation in creatinine level is in accordance to Toshiko et al.,[11] in mice, Joshua et al.,[16], Oriquat et al.,[17] in rat. As we know serum creatinine
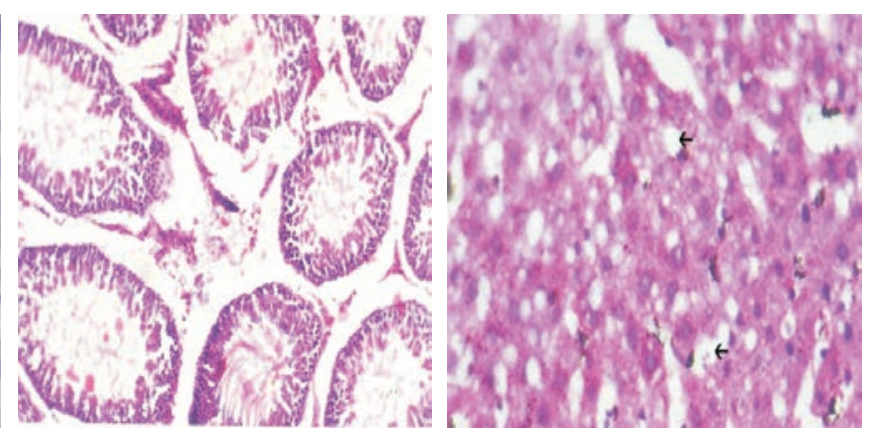

Figure-3. Testis: reduction in Figure-4. liver: Sever vacuoconcentration of matured sper- lization into hepatocyte (arrow) matozoa

concentration is one of the traditional screening indices for kidney function and renal structural integrity. It is well known that the mercury accumulate more in renal epithelium [18]. The rise in creatinine level might be due to damage produce in kidney tubules by mercury.

Significant $(P<0.05)$ decrease of $\mathrm{Hb}$, TEC, PCV observed in mercuric chloride treated groups on $28^{\text {th }}$ day. These finding findings were in consistent with Madureira et al.,[19], Hounkpatin et al., [20]. The decreased in $\mathrm{Hb}, \mathrm{PCV}$ and TEC might due to the oxidative damage. There might be increased generation of free radicals can cause cell membrane damage which in turn inactivate membrane $\mathrm{Na}^{+}-\mathrm{K}^{+}$ATPase, thereby allows entry of $\mathrm{Ca}^{+2}$ into the cell. The sustained increase in intracellular calcium leads to free radicals generations, which in turn produce further inhibition of $\mathrm{Na}^{+}-\mathrm{K}^{+}$ATPase [21]. Thus, the mercuric chloride mediated generation of free radicals and consequent oxidative damage to erythrocytes, or hematolysis [22] can cause mechanical fragility of plasma membrane, there by shortened RBC life span and its removal from the circulation. That favour lower level of RBCs. Significant $(P<0.05)$ decrease in TLC value observed in both mercury chloride treated groups. The decrease in TLC might be due to the toxic effect of orally given mercuric chloride.

A significant $(P<0.05)$ increase in neutrophils and decrease in lymphocyte was observed count in rats receiving mercuric chloride. While significant increase in monocytes and eosinophil count was also observed on the 28 day. In the present study, decrease in lymphocyte count might be due to the toxic effect of mercury on lymphocytopoesis. The decrease in $\mathrm{T}$ - 
lymphocyte populations in immune organs and altered cytokine gene expression might contribute to the immunotoxic effects of inorganic mercury [23]. Lymphocyte depletion was more severe in B cells than in $\mathrm{T}$ cells. This depletion was associated with partial lymphocyte activation (CD69+) and it was due to apoptosis rather than to necrosis. From these results it is concluded that increase in neutrophils count in all $\mathrm{HgCl}_{2}$ treated groups as compared to control might have attributed to deposition of mercury metal in visceral organs which initiated the inflammatory cascade.

The mercuric chloride toxic effect is due to its ability to adhere or to form link with cell enzymes of the respiratory chain and proteins, which alter the metabolism (mostly TCA cycle) of target cells in organs participating in its elimination. Mercury also provokes a vascular damage that favors vascular leakage into the tissue and development of intestinal edema [24]. Endothelial damage by ROS- reactive oxygen species could be the main sources for producing large scale hemorrhages in kidney, liver, brain and heart.

The mercury deposits in the liver, kidneys, nerve cells, heart and other skeletal muscles, whereas in chronic condition or treatment its deposition is observed predominantly in hard tissues (mostly bone and cartilage), reaching a critical concentration [25], after which it begins to be excrete through urine, faeces, saliva, milk and expiration [26]. This gives strong explanation for degenerative changes in the proximal convoluted tubules epithelium of kidneys [27, 28, and 29], liver [30] and lung, as established in this present experimental study. The aforesaid harmful actions in those vital organs are most likely due to the route of detoxification and elimination of mercury and its compounds via the same organs. The damage to involuntary muscles of heart (myocardium) and endothelium may additionally contribute to the pronounced degenerative changes in the cerebellum and cerebrum, which is the most oxygen sensitive observed in our experimental cases.

On the other side, mercury possesses a strong immunosuppressive action. This toxic-immuno-suppressive action is expressed by depletion of cell and degenerative changes in the spleen mesenterial lymph nodes and brain $[31,32]$.

\section{Conclusion}

Hence on the basis of serum biochemistry, hematology and pathological alteration it becomes clear that mercuric chloride exhibit considerable toxic effect on most vital organs. So there is an urgent need to develop preventive measures to containmercuric chloride toxicity.

\section{Authors' contributions}

TJS carried out the present investigation under guidance of BJP. MDJ and RBP helped in sample collection. DVJ drafted and revised the manuscript. All authors read and approved the final version of the manuscript.

\section{Acknowledgments}

The authors are thankful to The Head of the Department of veterinary pathology, S. D. Agricultural University for providing fund and facilities for this research.

\section{Competing interests}

The authors declare that they have no competing interests.

\section{References}

1. Bersenyi, A., Fekete, S., Hullar, I., Kadar, I., Szilagyi, M. and Glavits, R. (1999) Study of the soil plant (Carrot) animal cycle of nutritive and hazardous minerals in rabbit model. Acta Veterinaria Hunagarica. 47 (2): 181-190.

2. Emanuelli, T., Rocha, J.B.T., Periera, M.E., Prociuncula, L.O,, Morsch, V.M. and Martins, A.F. (1996) Effect of mercuric chloride intoxication and dimercaprol treatment on delta aminolevulinatedehydratase from brain, liver and kidney of adult mice. Pharm. Toxicol. 79: 136-43.

3. Esteva-Font C, Ballarin J, Fernandez-Llama, P. (2012) Molecularbiology of water and salt regulation in the kidney. Cell. Mol. LifeSci. 69:683-695.

4. Ansari, R.A.,Rizvi, S. A. A., Husain, K., Lymperopoulos, A. and Berndt, W. O. (2012) B Environ. Contam. Tox. 89(4): 699-703.

5. Lash LH (2011) Renal membrane transport of glutathione intoxicology and disease. Vet Pathol. 48:408-419.

6. Houston, M.C. (2011) Role of mercury toxicity in hypertension, cardiovascular disease, and stroke. J. Clin. Hypertens. (Greenwich).13:621-627.

7. Lenaz, G. (2012) Mitochondria and reactive oxygen species. Whichrole in physiology and pathology? Adv Exp Med Biol.942:93-136.

8. Scatena, R. (2012) Mitochondria and drugs. Adv Exp Med Biol. 942:329-346.

9. Vallee, B. L. And Umer, D. D. (1972) Biochemical effect of mercury, cadmium and lead. Ann. Rev. Biochem. 41:91.

10. Snedecor, G. W. and Cochran, W. G. (1980) Statistical Methods : 7th Edn. The Iowa State University Press. Ames. IOWA, USA.

11. Toshiko, T. K., Mieko, S., Akira, N., Nobuki, Y. and Nobumasa, L. (1998) Strain difference in sensitivity of mice to renal toxicity of inorganic mercury. J. Pharmacol. Exp. Ther. 285 (1): 335-341.

12. Ejebe, D.E., Nwokocha, C., Nwangwa, E.K., Ekene, N., Akonoghrere, R. and Ukwu, J. (2010) The Effects of Bitter Kola Supplemented Diet on Hepatotoxicity of Mercury in Wistar Rats. J. Appl. Sci. Environ. Manage. 14(1): 89-95.

13. Madhu Kumar, Mukesh Kumar, Sharma and Ashok Kumar. (2005) SpirulinaFuiformis : A food supplement against mercury induced hepatic toxicity. J. Health Sci. 51 (4): 424430.

14. El-Dermdash, F.M. (2001) Effect of selenium and mercury on the enzymatic activities and lipid peroxidation in brain, liver, and blood of rats. $J$ of Env Sci and Health Part-B-Pesticides Food Contaminants and Agri Waste; 36 (4): 489-499.

15. Merzoug, S., Toumi, M. L., Oumeddour, A., Boukhris, N., Baudin, B., Tahraoui, A. and Bairi, A. (2009) Effect of inorganic mercury on biochemical parameters in Wistar rat. J. Anim. Cell Biol. 3 (12): 222-230.

16. Joshua, R.E., Evangelos, A.L., Jacob, D.P. Peter, C.L. and Walter, C.P. (2007) A novel method for the evaluation of proximal tubule epithelial cellular necrosis in the intact rat kidney using ethidiumhomodimer. BMC Physiology. $7: 1$

17. Oriquat, G. A.,.Saleem, T.H.,.Naik, R.R.,.Moussa, S.Z.and 
Al-Gindy, R. M. (2012) A Sub-Chronic Toxicity Study of Mercuric Chloride in the Rat. Jordan J. Biol. Sci. 5(2):141-146.

18. Zalups, R.K. (1995) Progressive losses of renal mass and the renal and hepatic deposition of administered inorganic mercury. Toxicol. Appl. Pharmacol., 130 (1): 121-131.

19. Madureira, P, Cunha, E.M. and Aguas, A.P. (2007). Acute depletion and recovery of peritoneal B-lymphocytes in $\mathrm{BALB} / \mathrm{c}$ mice after a single injection of mercury chloride. Immunopharmacol. Immunotoxicol. 29(2):311-322.

20. Hounkpatin, A.S.Y., Johnson, R.C., Guédénon, P., Domingo, E., Alimba, C.G., Boko M. and Edorh P.A. (2012) Protective Effects of Vitamin C on Haematological Parameters in Intoxicated Wistar Rats with Cadmium, Mercury and Combined Cadmium and Mercury. Int. Res. J. Biological Sci. 1(8): 76-81.

21. Kumar, S.V.,Maitra, S. and Bhattacharya. S. (2002) In vitro binding of inorganic mercury to the plasma membrane of rat platelet affects $\mathrm{Na}+\mathrm{K}+-$ Atpase activity and platelet aggregation. Biometals. 15(1):51-7

22. Ichikawa H, Ronowicz K, Hicks M and Gebicki J.M., (1987) Lipid peroxidation is not the cause of lysis of human erythrocytes exposed to inorganic or methylmercury. Arch Biochem Biophys. 259(1): 46-51.

23. Sang Hyun Kim, Victor J. Johnson and Raghubir P. Sharma. (2003) Oral exposure to inorganic mercury alters $T$ lymphocyte phenotypes and cytokine expression in BALB/c mice, Arch. Toxicol. 613-620.

24. Sharma, D. C. (1988) Histochemical study of the metabolism and toxicity of mercury. Curr. Sci. 57: 483-485.

25. Ulfarson, U. (1969) The effect of the size of the dose on the distribution and excretion of mercury in rats after single intravenous of various compounds. Toxicol. Appl. Pharmacol. 15: 517-524.

26. Joselow, M., Goldwater, L. J. and Weinberg, S. B. (1967) Absorption and excretion of mercury in man. Arch. Environ. Hlth. 15: 64-66.

27. Ganote, C. E., Reimer, K. A. and Jennings, R. B. (1974) Acute mercuric chloridenephrotoxicity, an electron microscopic and metabolic study. Lab. Invest. 31: 633-647.

28. Carmignani, M., Boscole, P. Sabcheffoni, G., Ripanti, G.andCareli, G. (1988) Cardiovascular function, renal ultrastructure and tissue metal levels in rats with long-term exposure to mercuric chloride. Acta Med. Rom. 26: 287-297.

29. Oda, S.S and. El-Ashmawy, I. M. (2012) Protective Effect of Silymarin on Mercury-Induced Acute Nephro-Hepatotoxicity in Rats. Global Veterinaria. 9 (4): 376-383.

30. Mohammad A.M., Wadaan (2009) Effects of Mercury Exposure on Blood Chemistry and Liver Histopathology of Male Rats. Journal of Pharmacology and Toxicology, 4: 126-131.

31. Christensen, M. (1988) Toxicity and ultrastructural localization of mercuric chloride in cultured murine macrophages. Arch. Toxicol. 62: 440-446.

32. Rao, M. V. and Purohit, A. R. (2013) Histopathological effect in. cerebral hemisphere of rats exposed to mercury and its amelioration by melatonin. Res. J. Biotech. 8(1):26-32.

$* * * * * * * *$ 